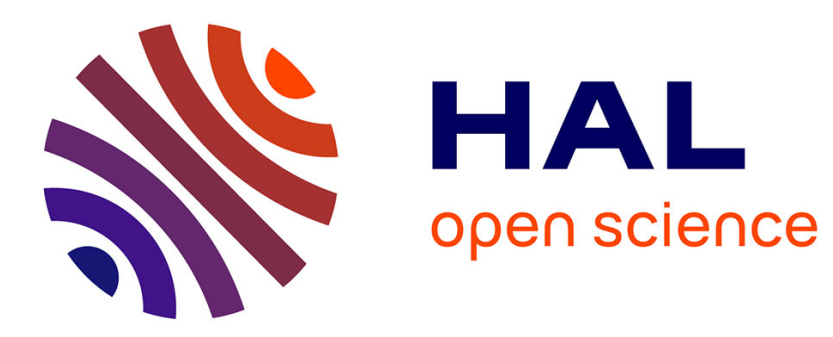

\title{
Towards Long Wavelength Absorbing Photodynamic Therapy Photosensitizers via the Extension of a [Ru(bipy) 3 ] 2+ Core
}

Johannes Karges, Olivier Blacque, Philippe Goldner, Hui Chao, Gilles Gasser

\section{- To cite this version:}

Johannes Karges, Olivier Blacque, Philippe Goldner, Hui Chao, Gilles Gasser. Towards Long Wavelength Absorbing Photodynamic Therapy Photosensitizers via the Extension of a $[\mathrm{Ru}(\mathrm{bipy})$ 3 ] 2+ Core. European Journal of Inorganic Chemistry, 2019, 2019 (32), pp.3704-3712. 10.1002/ejic.201900569 . hal-02273765

\section{HAL Id: hal-02273765 https://hal.science/hal-02273765}

Submitted on 29 Aug 2019

HAL is a multi-disciplinary open access archive for the deposit and dissemination of scientific research documents, whether they are published or not. The documents may come from teaching and research institutions in France or abroad, or from public or private research centers.
L'archive ouverte pluridisciplinaire HAL, est destinée au dépôt et à la diffusion de documents scientifiques de niveau recherche, publiés ou non, émanant des établissements d'enseignement et de recherche français ou étrangers, des laboratoires publics ou privés. 


\title{
Towards Long Wavelength Absorbing Photodynamic Therapy
}

\section{Photosensitizers via the Extension of a $\left[\operatorname{Ru}(\text { bipy })_{3}\right]^{2+}$ Core}

\author{
Johannes Karges, ${ }^{[\mathrm{a}]}$ Olivier Blacque, ${ }^{[\mathrm{b}]}$ Philippe Goldner, ${ }^{[\mathrm{c}]}{ }^{\mathrm{H}} \mathrm{Hu}$ Chao, ${ }^{[\mathrm{d}]}$ and Gilles Gasser ${ }^{[\mathrm{a}], \text { * }}$
}

\begin{abstract}
Complementary to classical treatment methods used against cancer, photodynamic therapy (PDT) has received increased attention over the last years. PDT relies on the generation of reactive oxygen species (ROS) upon light irradiation to trigger cell death. As the wavelength employed during such treatments directly influences the light penetration depth and therefore the possibility to treat deep seated tumours or large tumours, research efforts have been made towards the development of photosensitizers (PS) with an absorption in the phototherapeutic window (600-900 nm). To tackle this drawback we report herein the preparation and characterisation of new $\mathrm{Ru}(\mathrm{II})-$ containing PDT PSs, that are based on a $\left[\mathrm{Ru}(\text { bipy })_{3}\right]^{2+}$ core $(\mathbf{1}$; bipy: 2,2'-bipyridine) and that are extended with methyl groups (2) or vinyl dimethylamino groups (3). As anticipated with our design, we found a red-shift of $65 \mathrm{~nm}$ of the maximum absorption of complex 3 in comparison to complex 1 . In addition, we report on the in-depth photophysical properties as well as (photo-)cytotoxicity against cervical cancerous HeLa cells of the investigated compounds.
\end{abstract}

\section{Introduction}

Over the last decades, cancer has emerged to be one of the deadliest diseases worldwide. ${ }^{[1]} \mathrm{Next}$ to the classical treatments (e.g., chemotherapy, surgery and radiotherapy), the use of Photodynamic Therapy (PDT) has received increased attention

[a] J. Karges, Dr. G. Gasser

Chimie ParisTech, PSL University, CNRS, Institute of Chemistry for Life and Health Sciences, Laboratory for Inorganic Chemical Biology, 75005 Paris, France.

gilles.gasser@chimieparistech.psl.eu; www.gassergroup.com

[b] Dr. O. Blacque

Department of Chemistry, University of Zurich, Winterthurerstrasse 190, CH-8057, Zurich, Switzerland.

[c] Dr. P. Goldner

Chimie ParisTech, PSL University, CNRS, Institut de Recherche de Chimie Paris, 75005 Paris, France.

[d] Prof. H. Chao

MOE Key Laboratory of Bioinorganic and Synthetic Chemistry, School of Chemistry, Sun Yat-sen University, 510275 Guangzhou, People's Republic of China.

Supporting information for this article is given via a link at the end of the document. as a complementary medical technique to these blockbusters. PDT is based on the combination of light, a photoactive compound called a Photosensitizer (PS) and oxygen. Ideally, the PS should be nontoxic in the absence of light and generate highly toxic species upon light irradiation. The mechanism of action of PDT is based on the generation of reactive oxygen species (ROS). More specifically, upon light irradiation, the PS is excited to a singlet state, which can be transformed into an excited triplet state by an intersystem crossing (ISC) process. From there, the PS is able to influence its biological environment by two pathways, namely Type I and Type II. During a Type I reaction, an electron or proton is transferred to/from the PS from/to its biological surrounding. This leads to the generation of radicals and ROS like superoxides or hydroxyl radicals. In a Type II reaction, the energy of the exited triplet state of the PS is transferred to molecular oxygen $\left({ }^{3} \mathrm{O}_{2}\right)$ to produce singlet oxygen $\left({ }^{1} \mathrm{O}_{2}\right)$. This highly energetic form of oxygen is highly reactive. Consequently, during both pathways, ROS or ${ }^{1} \mathrm{O}_{2}$ react with its biological surrounding, generating cellular damages and therefore ultimately trigger cell death. ${ }^{[2]}$

The most commonly used PS for PDT treatments is Photofrin (Figure 1), which is approved for the treatment of bladder cancer, early stage lung cancer, oesophageal cancer and early non-small cell lung cancer in various countries. To date, the majority of approved PSs are based on a tetrapyrrolic scaffold. Due to their relatively similar structures, the majority of these compounds have a tendency to share the same disadvantages, which are 1) poor water solubility; 2) tedious synthesis; 3) photobleaching effect and 4) slow clearance from the body causing photosensitivity. At this stage, it is important to mention that some compounds based on a tetrapyrrolic scaffold do not share these limitations. ${ }^{[2 c, 3]}$ 

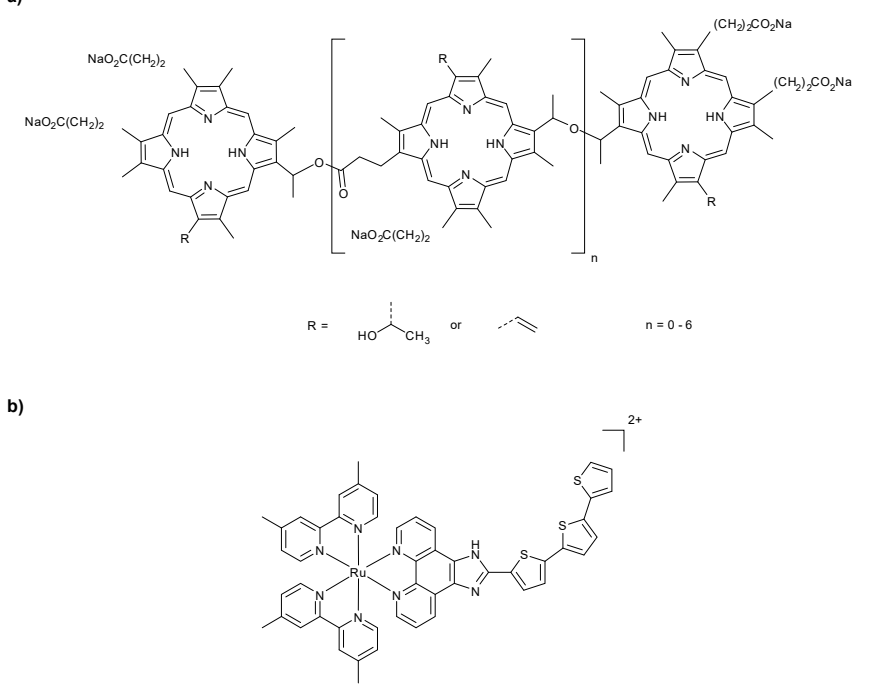

Figure 1. Structure of a) Photofrin and b) TLD-1433. $\left[R u(d m b)_{2}(I P-T T)\right]^{2+}$ ( $\mathrm{dmb}=4,4^{\prime}$-dimethyl-2,2'-bipyridine, IP-TT=2-(2',2":5",2' "-terthiophene)imidazol[4,5-f][1,10]phenanthroline).

To tackle these drawbacks, new classes of PDT PSs are currently being developed. Among the different classes, Ru(II) polypyridyl complexes seem to be excellent candidates. The majority of these compounds have generally a high water solubility, long luminescence decay, high ${ }^{1} \mathrm{O}_{2}$ production as well as a high chemical and photophysical stability. ${ }^{[4]}$ Therefore, it is not surprising that the complex TLD-1433 (Figure 1, $\lambda_{\mathrm{ex}}=525 \mathrm{~nm}$, $\varepsilon_{\max }=2000 \mathrm{M}^{-1} \mathrm{~cm}^{-1}, \Phi \sim 0.99$ in $\mathrm{CH}_{3} \mathrm{CN}$ ) has just completed phase I clinical trial as a novel PDT PS for the treatment of bladder cancer. ${ }^{[4 h, 5]}$

To date, most studied Ru(II) polypyridyl complexes lack significant absorption in the phototherapeutic window (600-900 $\mathrm{nm}){ }^{[6]}$ It is well-established that the wavelength used during treatments directly correlates with the tissue penetration depth. Longer wavelengths are able to penetrate deeper in the tissue and are hence potentially able to treat deeper-seated tumours or larger tumours. Additionally, as longer wavelengths are less energetic, less photodamage caused by the light source has been associated with treatments at longer wavelengths. Based on this, PSs with an absorption at wavelengths in the phototherapeutic window are sought after. ${ }^{[7]}$

With the aim to develop Ru(II) polypyridyl complexes with a redshift absorption in view of applications as PDT PSs, we have extended the parent complex $\left[\operatorname{Ru}(\text { bipy })_{3}\right]^{2+}$ (1) (bipy $=2,2^{\prime}-$ bipyridine) with methyl groups (2) and the conjugated system with vinyl dimethylamino groups (3) (Figure 2). Recent investigations have shown that the $\pi$-extension of the bipy core of the $\mathrm{Ru}(\mathrm{II})$ polypyridine complex caused a red shift of the absorption of the resulting complex. ${ }^{[8]}$ In addition, previous systematic studies of differently substituted Ru(II) polypyridine complex have indicated that dialkylamino substituents strongly promote a desired red shift in absorption. ${ }^{[9]}$ Combining these concepts, we report here compound 3, with an extended $\pi$-system and dimethylamine groups, which was indeed found to have a red-shifted absorption of $65 \mathrm{~nm}$ in comparison to complex 1 and an absorption in the phototherapeutic window as well as highly increased extinction coefficients. Importantly, we could show the ability of this compound to produce ${ }^{1} \mathrm{O}_{2}$ at longer wavelengths as well as to cause phototoxicity at this wavelength in cancerous cells while having no observed dark toxicity.

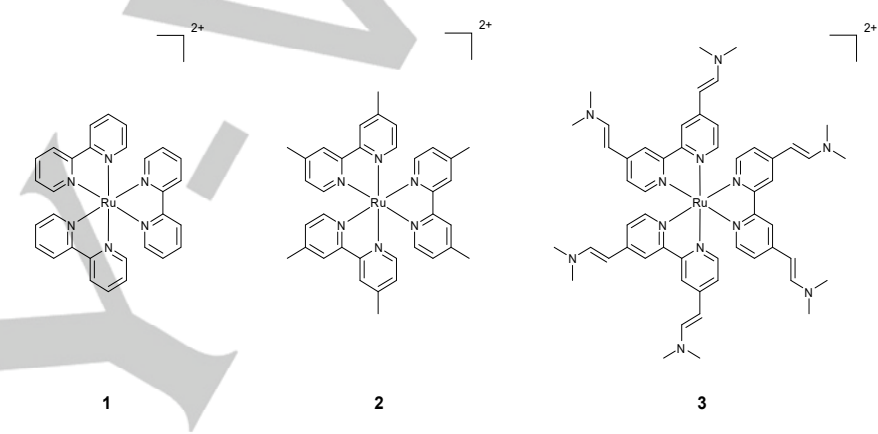

Figure 2. Chemical structures of the investigated compounds in this study. The complexes were isolated as $\mathrm{PF}_{6}$ salts

\section{Results and Discussion}

\section{Synthesis and Characterisation}

The complexes synthesised in this work are shown in Figure 2. Compound 1 was obtained from a commercial source whereas 2 was synthesised as previously reported by complexation of $\mathrm{RuCl}_{2} \mathrm{dmsO}_{4}$ with $4,4^{\prime}$-dimethyl-2,2'-bipyridine. ${ }^{[10]}$ To the best of our knowledge, the synthesis the complex 3 has not been yet reported. The ligand ( $\left.E, E^{\prime}\right)-4,4$ '-bis( $N, N$-dimethylaminovinyl)-2,2'bipyridine present in complex 3 was synthesised as previously reported. ${ }^{[11]}$ However, complexation attempts of this ligand using similar conditions to complex 2 (e.g. in EtOH or DMF as well as addition of $\mathrm{AgBF}_{4}$ to remove the $\mathrm{Cl}$ ligands by precipitation of $\mathrm{AgCl})$ were unsuccessful. Based on these findings, the synthetic procedure was changed (Scheme 1). As the first step, the complexation of $\mathrm{RuCl}_{2} \mathrm{dmsO}_{4}$ with 4,4'-dimethyl-2,2'-bipyridine was performed. In a second step, an enamination reaction with tert-butoxy bis(dimethylamino)methane (Bredereck reagent) was 
accomplished to obtain the desired compound 3 . The signals in the NMR for 3 were correlated to their protons/carbons in the structure (numbering of the complex can be found in Figure $\mathrm{S} 1$ ) via 2D-NMR (Figures S4 and S5). The identity of complex 3 was confirmed by ${ }^{1} \mathrm{H}$ - and ${ }^{13} \mathrm{C}-\mathrm{NMR}$, ESI-HRMS (Figure S2, S3, S6) and the purity of all compounds verified by elemental analysis.

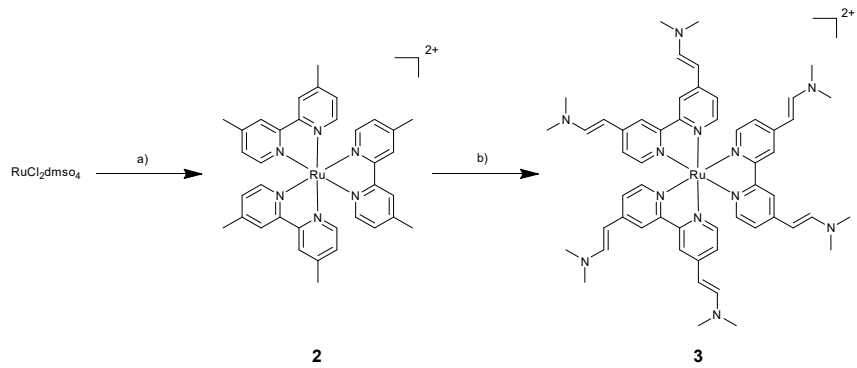

Scheme 1. Synthesis of complexes 2 and 3. a) 4,4'-dimethyl-2,2'-bipyridine, DMF, reflux, $12 \mathrm{~h}$, nitrogen atmosphere, 92\%; b) tert-butoxy bis(dimethylamino)methane, DMF, $140^{\circ} \mathrm{C}, 40 \mathrm{~h}$, nitrogen atmosphere, $85 \%$.

\section{X-ray crystallography}

The crystal structures of 4,4'-bis( $N, N$-dimethylaminovinyl)-2,2'bipyridine and 2 have been determined by single crystal X-ray diffraction studies. Crystal data, structure refinement parameters and molecular structures are presented in Table $\mathrm{S} 1$ as well as Figures 3 and S7. The crystal structure of 4,4'-bis $(N, N$ dimethylaminovinyl)-2,2'-bipyridine presented in the manuscript is a new monoclinic polymorph (a) of the previous structure (b) reported by Viau et al. in 2003.[12] The asymmetric unit in a contains one and a half molecules: one of the independent molecules lies on a center of inversion located in the middle of the central $C-C$ bond while the second one occupies a general position. In both polymorphs the bipyridine derivative exhibits a classical transoid arrangement due to the repulsion of the nitrogen lone pairs and a $E$ configuration of the enamine double bonds. Polymorphs $\mathbf{a}$ and $\mathbf{b}$ significantly differ from each other in the relative orientation of the $\mathrm{C}=\mathrm{C}$ double bonds of the enamine moieties with the central rings. Indeed, in a they adopt a s-trans conformation with respect to $\mathrm{C} 3-\mathrm{C} 4, \mathrm{C} 12-\mathrm{C} 13$ and $\mathrm{C} 20-\mathrm{C} 21$ (Figure S7) while in b a s-cis conformation is observed (see Figure S8). In our crystals the molecules are linked by $\mathrm{C}-\mathrm{H} \cdots \mathrm{N}$ and $\mathrm{C}-\mathrm{H} \cdots \mathrm{m}$ interactions. In the structure of the trisbipyridyl ruthenium(II) complex 2 the central $\mathrm{Ru}$ atom is expectedly coordinated to the six nitrogen atoms of the three substituted bipyridines in a distorted octahedral geometry. The complex cations crystallized with $\mathrm{PF}_{6}{ }^{-}$counter-ions and solvent molecules of diethyl ether in a ration $1 / 2 / 1$. It is interesting to note that the crystal structure of $\mathbf{2}$ is isostructural with the previously reported crystal structure of the iron complex [Fe(4,4'-dimethyl-2,2'dipyridyl) $\left.)_{3}\right]\left[\mathrm{PF}_{6}\right]_{2}$ (Figure S9). ${ }^{[13]}$ In the crystal, ions and solvent molecules are linked together through $\mathrm{C}-\mathrm{H} \cdots \mathrm{F}$ and $\mathrm{C}-\mathrm{H} \cdots \mathrm{O}$ interactions. Despite the numerous aromatic rings of complex 2 no $\pi$.... $\pi$ or $\mathrm{C}-\mathrm{H} . . . \pi$ interactions are observed.

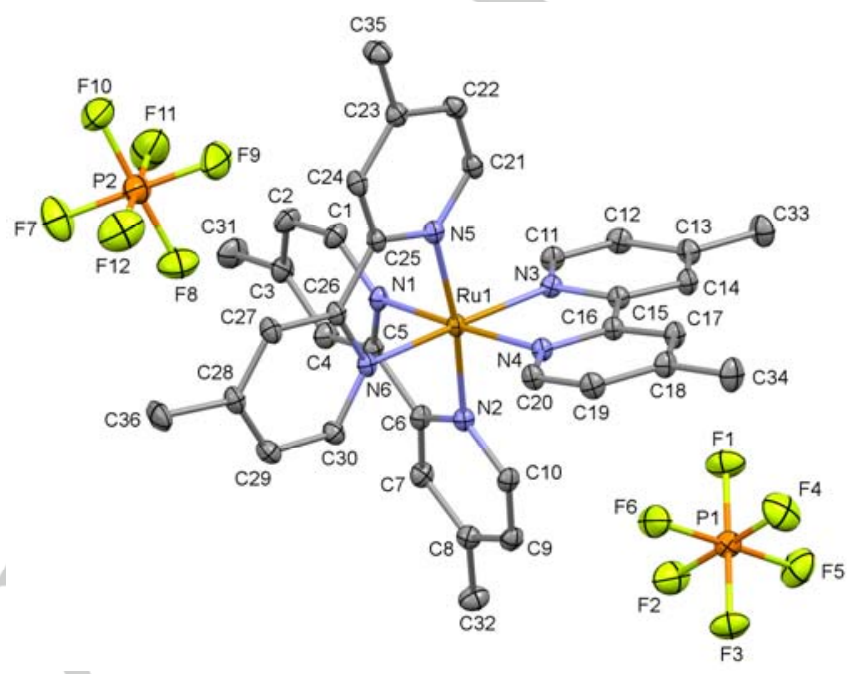

Figure 3. Molecular structure of compound 2. The thermal ellipsoids are drawn at the $30 \%$ probability level and all $\mathrm{H}$ atoms and the solvent molecule of diethyl ether are omitted for clarity.

\section{Photophysical properties}

The photophysical properties of the complexes were then evaluated to assess their potential as PDT PSs. To investigate this, we have measured the absorption of complexes 1-3 in $\mathrm{CH}_{3} \mathrm{CN}$ (Figure 4, Table 1). Typically, $\mathrm{Ru}(\mathrm{II})$ polypyridyl complexes have, as the lowest energy absorption band, a spinallowed metal-to-ligand charge transfer (MLCT) transition, which occurs for the prototype complex $\left[\mathrm{Ru}(\mathrm{bpy})_{3}\right]^{2+} \mathbf{1}$ at $450 \mathrm{~nm}$. The band at $285 \mathrm{~nm}$ was assigned to spin-allowed ligand-centered (LC) transition and the shoulders around $350 \mathrm{~nm}$ to metalcentered (MC) transitions. ${ }^{[6]}$ The comparison between complexes $\mathbf{1}$ and $\mathbf{2}$ shows only small differences indicating that the additional methyl groups in $\mathbf{2}$ do not significantly influence the absorption properties. On the contrary, the absorption of complex $\mathbf{3}$ was highly modified with a strong increase of the extinction coefficient as well as a strong red-shift of $65 \mathrm{~nm}$ of the maximum of the MLCT transition caused by the extension of the $\pi$-system as well as the insertion of dimethylamine groups at the terminal end. Importantly, the absorption tail of the compound is in the desired phototherapeutic window (600-900 nm). For further investigation 
of the excited state, the emission properties of the complexes were investigated upon excitation of the compounds in $\mathrm{CH}_{3} \mathrm{CN}$ at $355 \mathrm{~nm}$. The emission signal was measurable between 550-850 $\mathrm{nm}$ (Figure S10) with a maximum at $622 \mathrm{~nm}$ for complex 2 and $621 \mathrm{~nm}$ for complex 3 . Comparison to the standard compound 1 $\left(\Phi_{\mathrm{em}}=0.059\right)$ shows that complex 2 has an increased emission $\left(\Phi_{\mathrm{em}}=0.083\right)$ whereas complex 3 is only weakly emitting and could only be detected at the detection limit of our used setup. These results fit with those of a recent study which compared different 4,4'- $\pi$-conjugated[2,2']-bipyridines and which found that $\left(E, E^{\prime}\right)-4,4^{\prime}$-bis ( $N, N^{\prime}$-dimethylaminovinyl)-2,2'-bipyridine itself already had a low fluorescence quantum yield of 0.015 in dichloromethane. ${ }^{[14]}$ As an additional characterisation of the excited state, the luminescence lifetimes in degassed and air saturated $\mathrm{CH}_{3} \mathrm{CN}$ upon excitation at $355 \mathrm{~nm}$ were determined (Figure S11-S13). The measured lifetimes (Table 1) were found to be in the same range as for other investigated $\mathrm{Ru}(\mathrm{II})$ poylpyridine complexes. ${ }^{[9]}$ Importantly, the lifetimes of the excited state is strongly decreasing in the presence of air.

Table 1. Spectroscopic properties of the investigated complexes 1-3 in $\mathrm{CH}_{3} \mathrm{CN}$ at room temperature. $\lambda_{\mathrm{em}}=$ emission maximum, $\Phi_{\mathrm{em}}=$ luminescence quantum yield, $\mathrm{T}=$ lifetime.

\begin{tabular}{llllll}
\hline & $\begin{array}{c}\text { UV/Vis } \boldsymbol{\Lambda} / \mathbf{n m} \\
\left(\boldsymbol{\varepsilon} / \mathbf{M}^{-1} \mathbf{c m}^{-1} \mathbf{1 0}^{-3}\right)\end{array}$ & $\begin{array}{c}\boldsymbol{\lambda}_{\mathrm{em}} / \\
\mathbf{n m}\end{array}$ & $\boldsymbol{\Phi}_{\mathrm{em}}$ & & $\mathbf{T} / \mathbf{n s}$ \\
\hline $\mathbf{1}$ & $\begin{array}{l}285(80.8), 450 \\
(14.6)\end{array}$ & 610 & 0.059 & 130 & 925 \\
\hline $\mathbf{2}$ & $\begin{array}{l}285(91.8), 325 \\
(13.3), 460(16.6)\end{array}$ & 622 & 0.083 & 109 & 1024 \\
\hline $\mathbf{3}$ & $\begin{array}{l}295(86.2), 385 \\
(149.7), 515(56.4)\end{array}$ & 621 & $<0.001$ & 76 & 410 \\
\hline
\end{tabular}

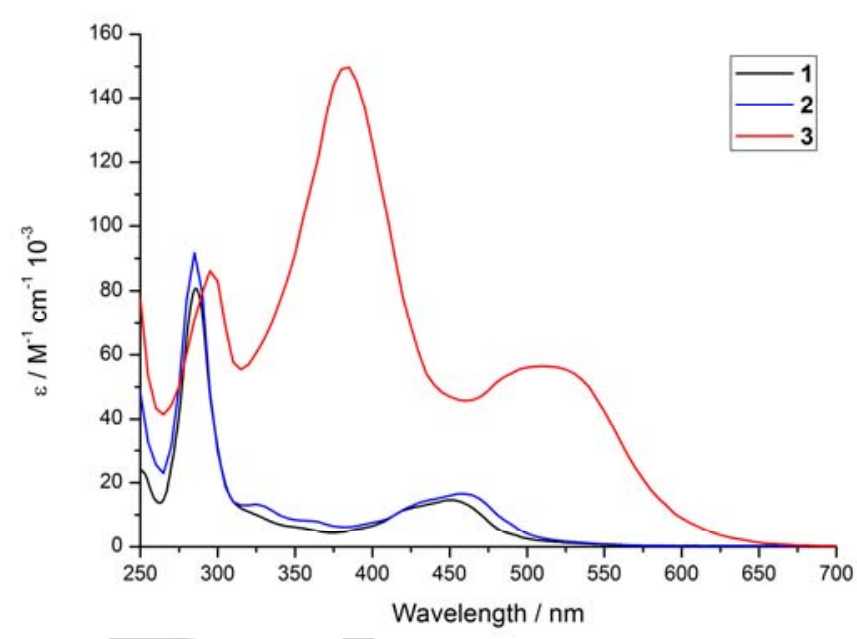

Figure 4. Absorption spectra of complexes 1-3 in $\mathrm{CH}_{3} \mathrm{CN}$.

\section{Singlet oxygen generation}

As discussed in the photophysical evaluation section, the lifetimes of the excited state of the investigated compounds are drastically decreasing in the presence of air indicating that the triplet state of the compound ( $\left.{ }^{3} \mathrm{PS}\right)$ is able to interact with molecular oxygen $\left({ }^{3} \mathrm{O}_{2}\right)$. As the active species for most applied PSs in PDT, the production of singlet oxygen $\left({ }^{1} \mathrm{O}_{2}\right)$ is responsible for most PDT effects. To investigate the ability of our compounds to generate ${ }^{1} \mathrm{O}_{2}$, we used two different methods, namely 1) direct by measurement of the phosphorescence of ${ }^{1} \mathrm{O}_{2}$ or 2) indirect by measurement of the change in absorbance of a reporter molecule. ${ }^{[15]}$ The results presented in Table 2 show that compounds 1 and 2 are generating ${ }^{1} \mathrm{O}_{2}$ decently whereas 3 generates ${ }^{1} \mathrm{O}_{2}$ only poorly.

Table 2. Singlet oxygen quantum yields in $\mathrm{CH}_{3} \mathrm{CN}$ and aqueous solution. Average of three independent measurements, $\pm 10 \%$.

\begin{tabular}{|c|c|c|c|c|c|c|}
\hline & $\begin{array}{c}\text { direct } \\
450 \mathrm{~nm} \\
\mathrm{CH}_{3} \mathrm{CN}\end{array}$ & $\begin{array}{c}\text { direct } \\
450 \mathrm{~nm} \\
\mathrm{D}_{2} \mathrm{O}\end{array}$ & $\begin{array}{l}\text { indirect } \\
450 \mathrm{~nm} \\
\mathrm{CH}_{3} \mathrm{CN}\end{array}$ & $\begin{array}{c}\text { indirect } \\
450 \mathrm{~nm} \\
\text { PBS }\end{array}$ & $\begin{array}{c}\text { indirect } \\
540 \mathrm{~nm} \\
\mathrm{CH}_{3} \mathrm{CN}\end{array}$ & $\begin{array}{c}\text { Indirect } \\
540 \mathrm{~nm} \\
\text { PBS }\end{array}$ \\
\hline 1 & $54 \%$ & $21 \%$ & $57 \%$ & $20 \%$ & n.d. ${ }^{\text {a) }}$ & n.d. ${ }^{\text {a) }}$ \\
\hline 2 & $66 \%$ & $25 \%$ & $64 \%$ & $27 \%$ & n.d. ${ }^{\text {a) }}$ & n.d. ${ }^{\text {a) }}$ \\
\hline 3 & n.d. & n.d. & $21 \%$ & $3 \%$ & $18 \%$ & $2 \%$ \\
\hline
\end{tabular}

n.d. $=$ not detectable.

n.d. ${ }^{\text {a) }}=$ not detectable due to missing absorbance at this wavelength.

\section{(Photo-)stability}

An important property of a molecule, which is envisioned to be used as a PDT PS, is its (photo-)stability. To investigate this, we have assessed the stability in organic solvents of our complexes as it was shown in previous works that this could already be problematic. ${ }^{[16]}$ For this purpose, the compounds were incubated in $\mathrm{CH}_{3} \mathrm{CN}$ and, in time intervals $(0,1,4,8,12,24,48 \mathrm{~h})$, their UV/Vis spectra measured. During the incubation in $\mathrm{CH}_{3} \mathrm{CN}$, no change in the spectra for all compounds (Figure S14-S16) could be detected indicating their stability in this solvent. As a second experiment, the stability in an aqueous PBS solution was investigated. Also, here, no decomposition was observed (Figure S17-S19), proving the stability of these compounds. Finally, as a third experiment, the complexes were incubated in human plasma and the stability of the complexes identified by an HPLC analysis. As an internal standard, caffeine was used, which has already been shown to be suitable for these experiments. ${ }^{[17]}$ After $48 \mathrm{~h}$ incubation, the compounds were extracted from the plasma and the HPLC chromatogram before and after the incubation compared. The analysis showed that no decomposition for the compounds 1 and 2 (Figure S20-S21) occurred. On the contrary, 
complex $\mathbf{3}$ was clearly transformed to a mixture of different kinds of unidentified products (Figure S22), clearly proving its decomposition. After investigation of the stability of the compounds in a biological environment, we have tested their stability upon irradiation in an air saturated $\mathrm{CH}_{3} \mathrm{CN}$ solution while monitoring their UV/Vis spectra in constant time intervals. The stability was compared to the PS Protoporphyrin IX (PpIX), which is well known to be photodegradating. The comparison between the spectra (Figure S23-S26) shows only a small decrease in absorption for $\mathbf{1}$ and $\mathbf{2}$ indicating only a small photobleaching effect. On the contrary, the bands of $\mathbf{3}$ strongly decrease and shift, proving its decomposition upon light exposure. Consequently, the modification caused by the irradiation was investigated by NMR spectroscopy. For this purpose, a solution of 3 in $\mathrm{CD}_{3} \mathrm{CN}$ was irradiated at $450 \mathrm{~nm}\left(30 \mathrm{~min}, 36.0 \mathrm{~J} / \mathrm{cm}^{2}\right)$ and the change in the ${ }^{1} \mathrm{H}-\mathrm{NMR}$ spectrum monitored. The compound was transformed in an unidentified mixture of different compounds (see Figure S27).

\section{Cellular Uptake}

A crucial parameter for the bioactivity of a molecule is its cellular uptake. To investigate this, compounds 1-3 were incubated for 4 $\mathrm{h}$ in the dark in human cervical carcinoma (HeLa) cells. The amount of the metal $\mathrm{Ru}$ inside the cells was then determined using inductively coupled plasma mass spectrometry (ICP-MS). The results (Figure 5) show that complex 3 has a much higher uptake than 1 or 2.

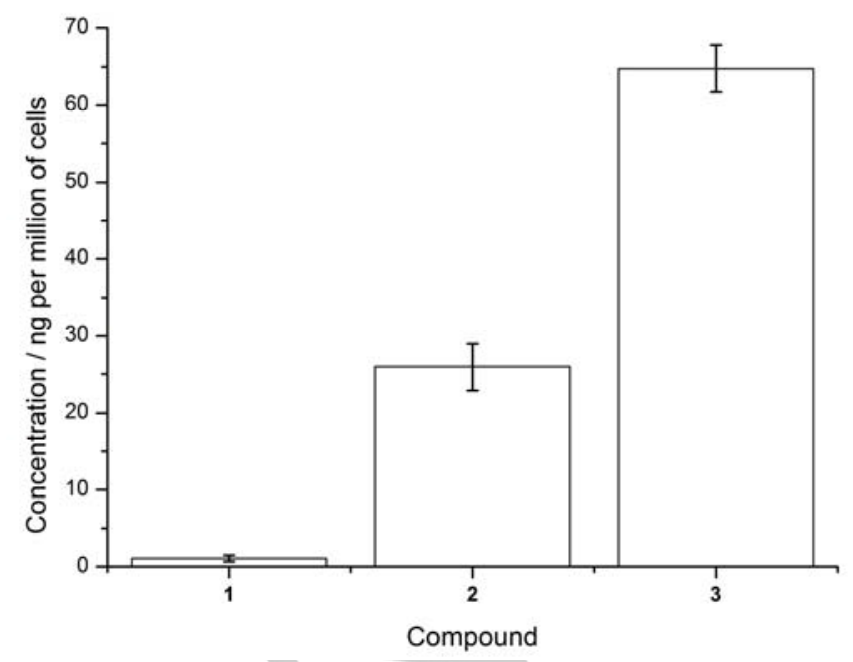

Figure 5. Comparison of the cellular uptake of complexes 1-3 after $4 \mathrm{~h}$ incubation in HeLa cells.

\section{Cytotoxicity and Phototoxicity}

After having assessed the chemical and photophysical properties of compounds 1-3, their influence on cell viability in the dark and upon light irradiation was investigated. For this purpose, the compounds were incubated in non-cancerous retinal pigment epithelium (RPE-1) and HeLa cells in the dark as well as upon light irradiation at $480 \mathrm{~nm}\left(10 \mathrm{~min}, 3.1 \mathrm{~J} / \mathrm{cm}^{2}\right)$ and $540 \mathrm{~nm}(40 \mathrm{~min}$, $\left.9.5 \mathrm{~J} / \mathrm{cm}^{2}\right)$. The obtained $\mathrm{IC}_{50}$ values were further compared with the chemotherapeutic drug cisplatin and the PS Protoporphyrin IX (PpIX) (Table 3). For all investigated complexes, no toxicity in the dark could be observed $\left(\mathrm{IC}_{50}>200 \mu \mathrm{M}\right)$, which is a desired characteristic for a potential PDT PS. Disappointingly, the exposure to light had only a small effect on the cell viability for the three compounds. While no toxicity was observed for compounds 1 and $\mathbf{2}$, compound 3 showed some phototoxicity. Of note, these findings are in agreement with a study of the $\left[\mathrm{Ru}(\text { bipy })_{3}\right]^{2+}$ complex which showed no dark and phototoxic effect in the high micromolar range. ${ }^{[18]}$ To evaluate the ability of a compound to act as a PS, the phototoxic index $(\mathrm{PI})$ is calculated as the ratio between the $\mathrm{IC}_{50}$ values in the dark and upon light exposure. For compound 3, a PI value of 1.3 at $480 \mathrm{~nm}$ and 1.4 at $540 \mathrm{~nm}$ for HeLa cells and 1.3 at $480 \mathrm{~nm}$ and 1.2 at $540 \mathrm{~nm}$ for RPE-1 cells was determined. These results demonstrate that $\mathbf{3}$ is able to have a slight phototoxic effect upon exposure to higher wavelength which is a desired characteristic for a PS. However, the obtained PI values are quite low in comparison to established PSs like PpIX. The results can be rationalised by the rather poor generation of singlet oxygen of this complex. One has also to highlight that the instability of this compound in human plasma and upon irradiation is extremely problematic and could also explain these poor biological results. Overall, the biological results obtained in this section are fitting with the ICP-MS experiments carried out which showed a much better cellular accumulation of complex 3 compared to complexes 1 and 2 .

Table 3. $I C_{50}$ values in the dark and upon irradiation at $480\left(10 \mathrm{~min}, 3.1 \mathrm{~J} / \mathrm{cm}^{2}\right)$ and $540 \mathrm{~nm}\left(40 \mathrm{~min}, 9.5 \mathrm{~J} / \mathrm{cm}^{2}\right)$ for complexes 1-3 in comparison to cisplatin and Protoporphyrin IX (PpIX) on non-cancerous retinal pigment epithelium (RPE-1) and human cervical carcinoma (HeLa) cells. Average of three independent measurements. n.d. = not determinable.

\begin{tabular}{|c|c|c|c|c|c|c|c|c|c|c|}
\hline & \multicolumn{5}{|c|}{ HeLa } & \multicolumn{5}{|c|}{ RPE-1 } \\
\hline & $\begin{array}{l}\mathrm{Da} \\
\text { rk }\end{array}$ & $\begin{array}{l}480 \\
\mathrm{~nm}\end{array}$ & PI & $\begin{array}{l}540 \\
\mathrm{~nm}\end{array}$ & PI & $\begin{array}{l}\mathrm{Da} \\
\text { rk }\end{array}$ & $\begin{array}{l}480 \\
\mathrm{~nm}\end{array}$ & PI & $\begin{array}{l}540 \\
\mathrm{~nm}\end{array}$ & $\mathbf{P I}$ \\
\hline 1 & $\begin{array}{l}>2 \\
00\end{array}$ & $\begin{array}{l}>20 \\
0\end{array}$ & $\begin{array}{l}\text { n. } \\
\text { d. }\end{array}$ & $\begin{array}{l}>20 \\
0\end{array}$ & $\begin{array}{l}\text { n. } \\
\text { d. }\end{array}$ & $\begin{array}{l}>2 \\
00\end{array}$ & $\begin{array}{l}>20 \\
0\end{array}$ & $\begin{array}{l}\text { n. } \\
\text { d. }\end{array}$ & $\begin{array}{l}>20 \\
0\end{array}$ & $\begin{array}{l}\mathrm{n} . \\
\mathrm{d} .\end{array}$ \\
\hline 2 & $\begin{array}{l}>2 \\
00\end{array}$ & $\begin{array}{l}>20 \\
0\end{array}$ & $\begin{array}{l}\mathrm{n} . \\
\mathrm{d} .\end{array}$ & $\begin{array}{l}>20 \\
0\end{array}$ & $\begin{array}{l}\text { n. } \\
\text { d. }\end{array}$ & $\begin{array}{l}>2 \\
00\end{array}$ & $\begin{array}{l}>20 \\
0\end{array}$ & $\begin{array}{l}\text { n. } \\
\text { d. }\end{array}$ & $\begin{array}{l}>20 \\
0\end{array}$ & $\begin{array}{l}\text { n. } \\
\text { d. }\end{array}$ \\
\hline
\end{tabular}




\begin{tabular}{lllllllllll}
\hline 3 & $>2$ & 152 & 1. & 146 & 1. & $>2$ & 158 & 1. & 161 & 1. \\
& 00 & $.4 \pm$ & 3 & $.3 \pm$ & 4 & 00 & $.5 \pm$ & 3 & $.7 \pm$ & 2 \\
& & 3.8 & & 4.2 & & & 8.1 & & 6.2 & \\
\hline PpIX & $>1$ & 2.5 & $>4$ & 2.1 & $>4$ & $>1$ & 3.8 & $>2$ & 3.1 & $>3$ \\
& 00 & \pm & 0 & \pm & 8 & 00 & \pm & 6 & \pm & 2 \\
& & 0.1 & & 0.3 & & & 0.1 & & 0.1 & \\
\hline Cispl & 10. & - & - & - & - & 29. & - & - & - & - \\
atin & $5 \pm$ & & & & & $3 \pm$ & & & & \\
& 0.8 & & & & & 1.4 & & & & \\
\hline
\end{tabular}

n.d. $=$ not determinable

\section{Conclusions}

In this study, we aimed to shift the absorption wavelength of the MLCT transition of Ru(II) polypyridyl complexes towards the red region to enable the use of longer wavelengths during PDT treatments. This would allow for deeper tissue penetration and therefore the possibility to treat deep-seated tumours and larger tumours. For this purpose, the $\left[\mathrm{Ru}(\text { bipy })_{3}\right]^{2+}$ complex was extended with methyl groups (2) and the conjugated system extended with vinyl dimethylamino groups (3). The compounds were characterized in-depth including by 2D-NMR techniques and single crystal X-ray crystallography. Whereas the photophysical properties of $\mathbf{2}$ were found to be in the same range as for the standard complex $\mathbf{1}$, compound 3 showed a highly increased absorption as shown by the very high extinction coefficients as well as a strong red shift of $65 \mathrm{~nm}$. Further analysis of the photophysical properties revealed that this compound was weakly emissive and has short excited state lifetimes. We assume that these properties are limiting the necessary energy transfer from the excited state ${ }^{3} \mathrm{PS}$ to molecular oxygen $\left({ }^{3} \mathrm{O}_{2}\right)$ to ultimately produce singlet oxygen $\left({ }^{1} \mathrm{O}_{2}\right)$. This probably explains the poor singlet oxygen quantum yield determined in this study for complex 3. Investigation of the stability of the compounds revealed that complexes 1 and 2 are stable in $\mathrm{CH}_{3} \mathrm{CN}$, PBS and human plasma whereas $\mathbf{3}$ decomposes in human plasma as well as upon light irradiation over time. Biological evaluation on the cancerous cell line HeLa and the non-cancerous cell line RPE-1 revealed no dark toxicity for any of the investigated complexes in this study. While no toxicity upon light exposure for compounds 1 and 2 could be observed, complex $\mathbf{3}$ showed some slight phototoxicity in the high micromolar range against cervical cancerous HeLa cells and importantly no measurable dark cytotoxicity. Despite unfavourable photophysical properties, 3 showed a stronger cytotoxic effect than the two other complexes $\mathbf{1}$ and $\mathbf{2}$. Quantification of the cellular uptake of the complexes by ICP-MS experiments rationalized this observation with complex 3 being much better taken up by HeLa cells than compounds 1 and 2 .
Overall this study demonstrates how the extension of the $\left[\mathrm{Ru}(\text { bipy })_{3}\right]^{2+}$ core through methyl groups (2) or vinyl dimethylamino groups (3) effects their photophysical properties including their absorption. We are currently investigating other options to synthesise Ru(II) polypyridyl complexes with a stronger luminescence, higher production of ${ }^{1} \mathrm{O}_{2}$ as well as stability in a biological environment as well as upon light exposure.

\section{Experimental Section}

\section{Materials}

All chemicals were obtained from commercial sources and used without further purification. Tris(2,2'-bipyridine)ruthenium(II) hexafluorophosphate $\left.\left[\mathrm{Ru}(\mathrm{bipy})_{3}\right]_{[\mathrm{PF}}\right]_{2}$ (1) was bought from Sigma Aldrich. The Ru(II) precursor $\mathrm{RuCl}_{2} \mathrm{dmsO}_{4}$ was synthesised as previously reported. ${ }^{[19]}$ The ligand $\left(E, E^{\prime}\right)-$ $4,4^{\prime}$-bis( $N, N$-dimethylaminovinyl)-2,2'-bipyridine present in complex 3 was synthesised as previously reported. ${ }^{[11]}$

\section{Instrumentation and methods}

${ }^{1} \mathrm{H}$ and ${ }^{13} \mathrm{C}$ NMR spectra were recorded on a Bruker $500 \mathrm{MHz}$ NMR spectrometer. Chemical shifts $(\delta)$ are reported in parts per million (ppm) referenced to tetramethylsilane $(\delta 0.00) \mathrm{ppm}$ using the residual proton solvent peaks as internal standards. Coupling constants $(\mathrm{J})$ are reported in Hertz $(\mathrm{Hz})$ and the multiplicity is abbreviated as follows: $\mathrm{s}$ (singlet), d (doublet), dd (doublet of doublet). ESI-MS experiments were carried out using a LTQ-Orbitrap XL from Thermo Scientific and operated in positive ionization mode, with a spray voltage at $3.6 \mathrm{kV}$. No Sheath and auxiliary gas was used. Applied voltages were 40 and $100 \mathrm{~V}$ for the ion transfer capillary and the tube lens, respectively. The ion transfer capillary was held at $275^{\circ} \mathrm{C}$. Detection was achieved in the Orbitrap with a resolution set to 100,000 (at $\mathrm{m} / \mathrm{z} 400$ ) and a $\mathrm{m} / \mathrm{z}$ range between $150-2000$ in profile mode. Spectrum was analyzed using the acquisition software XCalibur 2.1 (Thermo Fisher Scientific). The automatic gain control (AGC) allowed accumulation of up to $2^{*} 10^{5}$ ions for FTMS scans, Maximum injection time was set to $300 \mathrm{~ms}$ and $1 \mu$ scan was acquired. $10 \mu \mathrm{L}$ was injected using a Thermo Finnigan Surveyor HPLC system (Thermo Fisher Scientific) with a continuous infusion of methanol at $100 \mu \mathrm{L} \cdot \mathrm{min}^{-1}$. Elemental microanalyses were performed on a Thermo Flash 2000 elemental analyser. For analytic HPLC the following system has been used: $2 \mathrm{x}$ Agilent G1361 1260 Prep Pump system with Agilent G7115A 1260 DAD WR Detector equipped with an Agilent Pursuit XRs 5C18 (100A, C18 $5 \mu \mathrm{m}$ $250 \times 4.6 \mathrm{~mm}$ ) Column. The solvents (HPLC grade) were millipore water $(0.1 \%$ TFA, solvent $A)$ and acetonitrile $(0.1 \%$ TFA, solvent $B)$. Inductively coupled plasma mass spectrometry (ICP-MS) experiments were carried out on an iCAP RQ ICP-MS instrument (Thermo Fisher).

\section{Synthesis}

$\left[R u\left(4,4^{\prime} \text {-Dimethyl-2,2'-dipyridyl) }\right)_{3}\right]\left[\mathrm{PF}_{6}\right]_{2}$ (2) 
$\left[\mathrm{Ru}\left(4,4^{\prime}\right.\right.$-Dimethyl-2,2'-dipyridyl) 3$]\left[\mathrm{PF}_{6}\right]_{2}$ (2) was synthesized as previously published ${ }^{[8]}$ using $\mathrm{RuCl}_{2} \mathrm{dmsO}_{4}$. Experimental data fits with the literature. Purity of the sample was assessed by HPLC and elemental analysis. Elemental analysis calcd for $\mathrm{C}_{36} \mathrm{H}_{36} \mathrm{~F}_{12} \mathrm{~N}_{6} \mathrm{P}_{2} \mathrm{Ru}$ (\%): C 45.82, H 3.85, N 8.91; found: C 45.71, H 3.69, N 8.83.

\section{$\left[\mathrm{Ru}\left(\left(E, E^{\prime}\right)-4,4^{\prime}-\operatorname{Bis}(N, N \text {-dimethylaminovinyl)-2,2'-bipyridine })_{3}\right]\left[\mathrm{PF}_{6}\right]_{2}\right.$} (3)

$\left[\mathrm{Ru}\left(4,44^{\prime}\right.\right.$-Dimethyl-2,2'-dipyridyl) 3$]\left[\mathrm{PF}_{6}\right]_{2} \quad$ (2) $\quad(188 \mathrm{mg}, \quad 0.20 \mathrm{mmol}$, 1.0 equiv.) was dissolved in dry DMF $(12 \mathrm{~mL})$ under nitrogen atmosphere and tert-Butoxy bis(dimethylamino)methane $(0.9 \mathrm{~mL}, \quad 4.36 \mathrm{mmol}$, 21.8 equiv.) was added slowly. The mixture was heated at $140^{\circ} \mathrm{C}$ for 40 h. The solution was then cooled down and a sat. aqueous solution of $\mathrm{NH}_{4} \mathrm{PF}_{6}$ was added. The crude product, which precipitated as a PF6 salt was collected by filtration and washed with $\mathrm{H}_{2} \mathrm{O}$ and $\mathrm{Et}_{2} \mathrm{O}$. The product was isolated via fractionated precipitation from $\mathrm{CH}_{3} \mathrm{CN}$ by adding dropwise $\mathrm{Et}_{2} \mathrm{O} .215 \mathrm{mg}$ of $\mathbf{3}(0.17 \mathrm{mmol}, 85 \%)$ were yielded as a dark red solid. ${ }^{1} \mathrm{H}$ NMR ( $\left.\mathrm{CD}_{3} \mathrm{CN}, 500 \mathrm{MHz}\right): 7.98$ (d, $\left.{ }^{4} \mathrm{~J}=2.0 \mathrm{~Hz}, 6 \mathrm{H}, \mathrm{H} 3\right), 7.45$ (d, ${ }^{3} \mathrm{~J}=13.4$ $\mathrm{Hz}, 6 \mathrm{H}, \mathrm{H} 8$ ), 7.24 (d, ${ }^{3} J=6.2 \mathrm{~Hz}, 6 \mathrm{H}, \mathrm{H6}$ ), $6.90\left(\mathrm{dd},{ }^{3,4} \mathrm{~J}=6.2,2.0 \mathrm{~Hz}, 6 \mathrm{H}\right.$, $\mathrm{H} 5), 5.09\left(\mathrm{~d},{ }^{3} \mathrm{~J}=13.4 \mathrm{~Hz}, 6 \mathrm{H}, \mathrm{H} 7\right), 2.94(\mathrm{~s}, 36 \mathrm{H}, \mathrm{H} 10) .{ }^{13} \mathrm{C}-\mathrm{NMR}\left(\mathrm{CD}_{3} \mathrm{CN}\right.$, $125 \mathrm{MHz}$ ): $\delta=157.8$ (C2), 150.2 (C4), 150.0 (C6), 147.0 (C8), 120.2 (C5), 116.7 (C3), 93.0 (C7), 40.9 (C10). ESI-HRMS (pos. detection mode): calcd for $\mathrm{C}_{54} \mathrm{H}_{66} \mathrm{~N}_{12} \mathrm{Ru} \mathrm{m} / \mathrm{z}[\mathrm{M}]^{2+}$ 492.2283; found: 492.2284. Elemental analysis calcd for $\mathrm{C}_{54} \mathrm{H}_{66} \mathrm{~F}_{12} \mathrm{~N}_{12} \mathrm{P}_{2} \mathrm{Ru}$ (\%): C 50.90, H 5.22, N 13.19; found: C 50.64, H 4.96, N 12.90 .

\section{X-ray crystallography}

$\mathrm{X}$-ray single-crystal data were collected at low temperatures, $160(1) \mathrm{K}$ for 4,4'-bis( $N, N$-dimethylaminovinyl)-2,2'-bipyridine and at 183(1) $\mathrm{K}$ for compound 2 , with an Oxford liquid-nitrogen Cryostream cooler on a Rigaku OD XtaLAB Synergy Dualflex (Pilatus 200K detector) diffractometer. A single wavelength $X$-ray source from a micro-focus sealed $X$-ray tube were used with the $\mathrm{Cu} \mathrm{K}_{\alpha}$ radiation $(\lambda=1.54184 \AA)^{[20]}$ for both analyses. The selected single crystals were mounted using polybutene oil on a flexible loop fixed on a goniometer head and transferred to the diffractometer. Preexperiments, data collections, data reductions and analytical absorption corrections $^{[21]}$ were performed with the program suite CrysAlisPro. ${ }^{[22]}$ Using Olex2, ${ }^{[23]}$ the structures were solved with the SHELXT ${ }^{[24]}$ small molecule structure solution program and refined with the SHELXL2018/3 program package ${ }^{[25]}$ by full-matrix least-squares minimization on $F^{2}$. Molecular graphics were created using Mercury 4.0.[26] The crystal data collections and structure refinement parameters are summarized in Table S1. CCDC 1914096 (for 2) and CCDC 1914097 (for 4,4'-bis(N,Ndimethylaminovinyl)-2,2'-bipyridine) contain the supplementary crystallographic data for these compounds, and can be obtained free of charge from the Cambridge Crystallographic Data Centre via www.ccdc.cam.ac.uk/data request/cif.

Spectroscopic measurements
The absorption of the samples has been measured with a SpectraMax M2 Spectrometer (Molecular Devices). The emission was measured by irradiation of the sample in fluorescence quartz cuvettes (width $1 \mathrm{~cm}$ ) using a NT342B Nd-YAG pumped optical parametric oscillator (Ekspla) at 355 $\mathrm{nm}$. Luminescence was focused and collected at right angle to the excitation pathway and directed to an Acton SP-2300i monochromator (Princeton Instruments). As a detector a PI-Max 4 CCD camera (Princeton Instruments) has been used.

\section{Luminescence quantum yield measurements}

For the determination of the luminescence quantum yield, the samples were prepared in a not degassed $\mathrm{CH}_{3} \mathrm{CN}$ solution with an absorbance of 0.1 at $355 \mathrm{~nm}$. This solution was irradiated in fluorescence quartz cuvettes (width $1 \mathrm{~cm}$ ) using a NT342B Nd-YAG pumped optical parametric oscillator (Ekspla) at $355 \mathrm{~nm}$. The emission signal was focused and collected at right angle to the excitation pathway and directed to an Acton SP-2300i monochromator (Princeton Instruments). As a detector a XPI-Max 4 CCD camera (Princeton Instruments) has been used. The luminescence quantum yields were determined by comparison with the reference $\left[\mathrm{Ru}(\text { bipy })_{3}\right] \mathrm{Cl}_{2}$ in $\mathrm{CH}_{3} \mathrm{CN}\left(\Phi_{\mathrm{em}}=5.9 \%\right)^{[27]}$ applying the following formula:

$$
\begin{gathered}
\Phi_{\text {em, sample }}=\Phi_{\text {em, ref }}{ }^{*}\left(F_{\text {ref }} / F_{\text {sample }}\right) *\left(I_{\text {sample }} / I_{\text {ref }}\right)^{*}\left(n_{\text {sample }} / \mathrm{n}_{\text {ref }}\right)^{2} \\
F=1-10^{-A}
\end{gathered}
$$

$\Phi_{\mathrm{em}}=$ luminescence quantum yield, $\mathrm{F}=$ fraction of light absorbed, $I=$ integrated emission intensities, $\mathrm{n}=$ refractive index, $\mathrm{A}=$ absorbance of the sample at irradiation wavelength.

\section{Lifetime measurements}

For the determination of the lifetimes, the samples were prepared in an air saturated and in a degassed $\mathrm{CH}_{3} \mathrm{CN}$ solution with an absorbance of 0.2 at $355 \mathrm{~nm}$. This solution was irradiated in fluorescence quartz cuvettes (width $1 \mathrm{~cm}$ ) using a NT342B Nd-YAG pumped optical parametric oscillator (Ekspla) at $355 \mathrm{~nm}$. The emission signal was focused and collected at right angle to the excitation pathway and directed to an Acton SP-2300i monochromator (Princeton Instruments). As a detector a R928 photomultiplier tube (Hamamatsu) has been used.

\section{Singlet oxygen measurements Direct evaluation}

The samples were prepared in an air saturated $\mathrm{CH}_{3} \mathrm{CN}$ or $\mathrm{D}_{2} \mathrm{O}$ solution with an absorbance of 0.2 at $450 \mathrm{~nm}$. This solution was irradiated in fluorescence quartz cuvettes (width $1 \mathrm{~cm}$ ) using a mounted M450LP1 LED (Thorlabs) whose irradiation, centered at $450 \mathrm{~nm}$, has been focused with aspheric condenser lenses. The intensity of the irradiation has been varied using a T-Cube LED Driver (Thorlabs) and measured with an optical power and energy meter. The emission signal was focused and collected at right angle to the excitation pathway and directed to an Acton SP-2300i monochromator (Princeton Instruments). A longpass glass filter was placed in front of the monochromator entrance slit to cut off light at wavelengths shorter than $850 \mathrm{~nm}$. As a detector an EO-817L IR-sensitive liquid nitrogen cooled germanium diode detector (North Coast Scientific 
Corp.) has been used. The singlet oxygen luminesce at $1270 \mathrm{~nm}$ was measured by recording spectra from 1100 to $1400 \mathrm{~nm}$. For the data analysis, the singlet oxygen luminescence peaks at different irradiation intensities were integrated. The resulting areas were plotted against the percentage of the irradiation intensity and the slope of the linear regression calculated. The absorbance of the sample was corrected with an absorbance correction factor. As reference for the measurement rose bengal $(\Phi=76 \%)^{[28]}$ was used and the singlet oxygen quantum yields were calculated using the following formula:

$$
\begin{gathered}
\Phi_{\text {sample }}=\Phi_{\text {reference }}{ }^{*}\left(S_{\text {sample }} / S_{\text {reference }}\right) *\left(I_{\text {reference }} / I_{\text {sample }}\right) \\
I=I_{0} *\left(1-10^{-A}\right)
\end{gathered}
$$

$\Phi=$ singlet oxygen quantum yield, $S=$ slope of the linear regression of the plot of the areas of the singlet oxygen luminescence peaks against the irradiation intensity, $I$ = absorbance correction factor, 10 = light intensity of the irradiation source, $\mathrm{A}=$ absorbance of the sample at irradiation wavelength.

\section{- Indirect evaluation}

For the measurement in $\mathrm{CH}_{3} \mathrm{CN}$ : The samples were prepared in an airsaturated $\mathrm{CH}_{3} \mathrm{CN}$ solution containing the complex with an absorbance of 0.2 at the irradiation wavelength, $N, N$-dimethyl-4-nitrosoaniline aniline (RNO, $24 \mu \mathrm{M}$ ) and imidazole (12 mM). For the measurement in PBS buffer: The samples were prepared in an air-saturated PBS solution containing the complex with an absorbance of 0.1 at the irradiation wavelength, $\mathrm{N}, \mathrm{N}$ dimethyl-4-nitrosoaniline aniline (RNO, $20 \mu \mathrm{M})$ and histidine (10 mM). The samples were irradiated on 96 well plates with an Atlas Photonics LUMOS $\mathrm{BIO}$ irradiator for different times. The absorbance of the samples was measured during these time intervals with a SpectraMax M2 Microplate Reader (Molecular Devices). The difference in absorbance $\left(\mathrm{A}_{0}-\mathrm{A}\right)$ at 420 $\mathrm{nm}$ for the $\mathrm{CH}_{3} \mathrm{CN}$ solution or at $440 \mathrm{~nm}$ a PBS buffer solution was calculated and plotted against the irradiation times. From the plot the slope of the linear regression was calculated as well as the absorbance correction factor determined. The singlet oxygen quantum yields were calculated using the same formulas as used for the direct evaluation.

\section{Stability in $\mathrm{CH}_{3} \mathrm{CN}$ and PBS}

The stability of the compound in $\mathrm{CH}_{3} \mathrm{CN}$ and PBS was determined by UV/Vis spectroscopy. The compound was dissolved and stored at room temperature in the dark. The absorption spectrum from 250-700 nm was recorded with a SpectraMax M2 Microplate Reader (Molecular Devices) after each time interval $(0,1,4,8,12,24,48 \mathrm{~h})$ and compared.

\section{Stability in human plasma}

The stability of the complexes was evaluated with caffeine as an internal standard, which has already shown to be suitable for these experiments. ${ }^{[17]}$ The pooled human plasma was obtained from Biowest and caffeine from $\mathrm{TCl}$ Chemicals. Stock Solutions of the compounds $(40 \mu \mathrm{M})$ and caffeine $(20 \mu \mathrm{M})$ were prepared in DMSO. One aliquot of the solutions was added to $975 \mu \mathrm{L}$ of human plasma to a total volume of $1000 \mu \mathrm{L}$. Final concentrations of the compounds of $0.5 \mu \mathrm{M}$ n-and caffeine of $0.25 \mu \mathrm{M}$ were achieved. The resulting solution was incubated for $48 \mathrm{~h}$ at $37^{\circ} \mathrm{C}$ with continuous gentle shaking (ca. $300 \mathrm{rpm}$ ). The reaction was stopped after the incubation time by addition of $2 \mathrm{~mL}$ of methanol. The mixture was centrifuged for $45 \mathrm{~min}$ at $650 \mathrm{~g}$ at $4{ }^{\circ} \mathrm{C}$. The methanolic solution was filtered through a $0.2 \mu \mathrm{m}$ membrane filter. The solvent was evaporated under reduced pressure and the residue was dissolved in 1:1 (v/v) $\mathrm{CH}_{3} \mathrm{CN} / \mathrm{H}_{2} \mathrm{O}$ $0.1 \%$ TFA solution. The solution was filtered through a $0.2 \mu \mathrm{m}$ membrane filter and analysed using an HPLC System. Based on the big differences in lipophilicity, two different HPLC methods have been used. The solvents (HPLC grade) were millipore water ( $0.1 \%$ TFA, solvent A) and acetonitrile (solvent B). Method M1: 0-3 minutes: isocratic 95\% A (5\% B); 3- 17 minutes: linear gradient from $95 \% \mathrm{~A}(5 \% \mathrm{~B})$ to $0 \% \mathrm{~A}(100 \% \mathrm{~B}) ; 17-23$ minutes: isocratic $0 \% \mathrm{~A}(100 \% \mathrm{~B})$. Method $\mathrm{M} 2$ : $0-3$ minutes: isocratic $80 \%$ A (20\% B); $3-17$ minutes: linear gradient from $80 \% \mathrm{~A}(20 \% \mathrm{~B})$ to $0 \% \mathrm{~A}$ $(100 \% \mathrm{~B}) ; 17-23$ minutes: isocratic $0 \% \mathrm{~A}(100 \% \mathrm{~B})$. The flow rate was 1 $\mathrm{mL} / \mathrm{min}$ and the chromatogram was detected at $250 \mathrm{~nm}$.

\section{Photostability}

The samples were prepared in an air saturated $\mathrm{CH}_{3} \mathrm{CN}$ solution. To measure the photostability, the samples were irradiated at $450 \mathrm{~nm}$ in 96 well plates with an Atlas Photonics LUMOS BIO irradiator during time intervals from 0-10 min. The absorbance spectrum from 350-700 nm was recorded with a SpectraMax M2 Microplate Reader (Molecular Devices) after each time interval and compared.

\section{Cell culture}

Human cervical carcinoma (HeLa) cells were cultured using DMEM media and retinal pigment epithelium (RPE-1) cells using DMEM/F-12 with addition of $10 \%$ FBS and $1 \%$ penstrep. The cells were cultivated and maintained at $37{ }^{\circ} \mathrm{C}$ in a cell culture incubator at $37{ }^{\circ} \mathrm{C}$ with $5 \% \mathrm{CO}_{2}$ atmosphere. Before an experiment, the cells were passaged three times.

\section{Cellular uptake}

The cellular uptake of the complex was investigated by the determination of the Ru content inside the cells. The complex with a final concentration of $25 \mu \mathrm{M}(1 \% \mathrm{DMSO}, v \%)$ was incubated for $4 \mathrm{~h}$ at $37^{\circ} \mathrm{C}$ in the dark on a cell culture dish with a density of ca. $6 \cdot 10^{6}$ cells in $10 \mathrm{~mL}$ of media. After this time, the media was removed and the cells were washed with cell media. The cells were trypsinised, harvested, centrifuged and resuspended. The number of cells on each dish was accurately counted. Each sample was the digested using a $60 \% \mathrm{HNO}_{3}$ solution overnight. Each sample was diluted to solution of $2 \% \mathrm{HNO}_{3}$ in water. The Ru content was determined using an ICP-MS apparatus and comparing the results with the $\mathrm{Ru}$ references. The Ru content was then associated with the number of cells.

\section{(Photo-)cytotoxicity}

The cytotoxicity of the compounds was accessed by measuring the cell viability using a fluorometric resazurin assay. The cultivated cells were seeded in triplicates in 96 well plates with a density of 4000 cells per well in $100 \mu \mathrm{L}$ of media. After $24 \mathrm{~h}$ the medium was removed and the cells were 
treated with increasing concentrations of the compound diluted in cell media achieving a total volume of $200 \mu \mathrm{L}$. The cells were incubated with the compound for $4 \mathrm{~h}$. After this time, the media was removed and replaced with $200 \mu \mathrm{L}$ of fresh medium. For the phototoxicity studies, the cells were exposed to light with an Atlas Photonics LUMOS BIO irradiator. Each well was constantly illuminated with either a $480 \mathrm{~nm}$ or $540 \mathrm{~nm}$ irradiation. During this time, the temperature was maintained constantly at $37^{\circ} \mathrm{C}$. The cells were grown in the incubator for additional $44 \mathrm{~h}$. For the determination of the dark cytotoxicity, the cells were not irradiated and after the medium exchange directly incubated for $44 \mathrm{~h}$. After this time, the medium was replaced with fresh medium containing resazurin with a final concentration of $0.2 \mathrm{mg} / \mathrm{mL}$. After $4 \mathrm{~h}$ incubation, the amount of the fluorescent product resorufin was determined upon excitation at $540 \mathrm{~nm}$ and measurement its emission at $590 \mathrm{~nm}$ using a SpectraMax M2 Microplate Reader (Molecular Devices). The obtained data was analysed with the GraphPad Prism software.

\section{Acknowledgments}

Le Conseil Régional d'lle de France is acknowledged for providing financial support for the purchase of a $500 \mathrm{MHz}$ NMR spectrometer. This work was financially supported by an ERC Consolidator Grant PhotoMedMet to G.G. (GA 681679) and has received support under the program "Investissements d' Avenir" launched by the French Government and implemented by the ANR with the reference ANR-10-IDEX-0001-02 PSL (G.G.), the National Science Foundation of China (Nos. 21525105 and 21778079 for H.C.) and the 973 Program (No. 2015CB856301 for H.C.).

Keywords: Anticancer - Bioinorganic Chemistry - Medicinal Inorganic Chemistry - Metals in Medicine - Photodynamic Therapy

[1] a) A. Miller, B. Hoogstraten, M. Staquet, A. Winkler, Cancer 1981, 47, 207-214; b) R. Siegel, C. DeSantis, K. Virgo, K. Stein, A. Mariotto, T. Smith, D. Cooper, T. Gansler, C. Lerro, S. Fedewa, CA Cancer J. Clin 2012, 62, 220-241.

[2] a) T. J. Dougherty, C. J. Gomer, B. W. Henderson, G. Jori, D. Kessel, M. Korbelik, J. Moan, Q. Peng, JNCl: Journal of the National Cancer Institute 1998, 90, 889-905; b) D. E. Dolmans, D. Fukumura, R. K. Jain, Nat. Rev. Cancer 2003, 3, 380-387; c) A. E. O'Connor, W. M. Gallagher, A. T. Byrne, Photochem. Photobiol. 2009, 85, 1053-1074; d) J. D. Knoll, C. Turro, Coord. Chem. Rev. 2015, 282-283, 110-126; e) L. Zeng, P. Gupta, Y. Chen, E. Wang, L. Ji, H. Chao, Z.-S. Chen, Chem. Soc. Rev. 2017, 46, 5771-5804. a) F. Heinemann, J. Karges, G. Gasser, Acc. Chem. Res. 2017 50, 2727-2736; b) R. Bonnett, Chem. Soc. Rev. 1995, 24, 19-33; cM. Ethirajan, Y. Chen, P. Joshi, R. K. Pandey, Chem. Soc. Rev. 2011, 40, 340-362.

a) R. Padilla, W. A. Maza, A. J. Dominijanni, B. S. Winkel, A. J. Morris, K. J. Brewer, J. Photochem. Photobiol. A: Chem. 2016 322, 67-75; b) C. Mari, V. Pierroz, S. Ferrari, G. Gasser, Chem Sci. 2015, 6, 2660-2686; c) M. Jakubaszek, B. Goud, S. Ferrari, G Gasser, Chem. Commun. 2018, 54, 13040-13059; d) J. Karges, F.
Heinemann, F. Maschietto, M. Patra, O. Blacque, I. Ciofini, B. Spingler, G. Gasser, Bioorg. Med. Chem. 2019, 27, 2666-2675; e) J. Liu, C. Zhang, T. W. Rees, L. Ke, L. Ji, H. Chao, Coord. Chem. Rev. 2018, 363, 17-28; f) F. E. Poynton, S. A. Bright, S. Blasco, D. C. Williams, J. M. Kelly, T. Gunnlaugsson, Chem. Soc. Rev. 2017, 46, 7706-7756; g) J. Shum, P. K.-K. Leung, K. K.-W. Lo, Inorg. Chem. 2019, 58, 2231-2247; h) S. Monro, K. L. Colón, H. Yin, J. Roque III, P. Konda, S. Gujar, R. P. Thummel, L. Lilge, C. G. Cameron, S. A. McFarland, Chem. Rev. 2019, 119, 797-828; i) J. Karges, O. Blacque, M. Jakubaszek, B. Goud, P. Goldner, G. Gasser, J. Inorg. Biochem. 2019, 198, 110752; j) M. Jakubaszek, J. Rossier, J. Karges, J. Delasoie, B. Goud, G. Gasser, F. Zobi, Helv. Chim. Acta 2019, accepted.

[5] a) J. Fong, K. Kasimova, Y. Arenas, P. Kaspler, S. Lazic, A Mandel, L. Lilge, Photoche.Photobiol.Sci. 2015, 14, 2014-2023; b) P. Kaspler, S. Lazic, S. Forward, Y. Arenas, A. Mandel, L. Lilge, Photochem. Photobiol. Sci. 2016, 15, 481-495; c.

[6] a) C. Mari, V. Pierroz, R. Rubbiani, M. Patra, J. Hess, B. Spingler, L. Oehninger, J. Schur, I. Ott, L. Salassa, Chem. Eur. J. 2014, 20 14421-14436; b) C. Mari, V. Pierroz, A. Leonidova, S. Ferrari, G. Gasser, Eur. J. Inorg. Chem. 2015, 2015, 3879-3891; c) C. Mari, R. Rubbiani, G. Gasser, Inorg. Chim. Acta 2017, 454, 21-26; d) C Mari, H. Huang, R. Rubbiani, M. Schulze, F. Würthner, H. Chao, G. Gasser, Eur. J. Inorg. Chem. 2017, 2017, 1745-1752; e) H. Huang, B. Yu, P. Zhang, J. Huang, Y. Chen, G. Gasser, L. Ji, H. Chao, Angew. Chem. Int. Ed. 2015, 54, 14049-14052; f) S. Campagna, F. Puntoriero, F. Nastasi, G. Bergamini, V. Balzani, in Photochemistry and Photophysics of Coordination Compounds I (Eds.: V. Balzani, S. Campagna), Springer Berlin Heidelberg, Berlin, Heidelberg, 2007, pp. 117-214;

[7] a) K. Ogawa, Y. Kobuke, Anti-Cancer Agents Med. Chem. 2008, 8, 269-279; b) B. C. Wilson, W. P. Jeeves, D. M. Lowe, Photochem. Photobiol. 1985, 42, 153-162.

[8] a) C. Mari, H. Huang, R. Rubbiani, M. Schulze, F. Würthner, H. Chao, G. Gasser, Eur. J. Inorg. Chem. 2017, 1745-1752; b) B. J. Coe, L. A. Jones, J. A. Harris, B. C. Brunschwig, I. Asselberghs, K. Clays, A. Persoons, J. Garin, J. Orduna, J. Am. Chem. Soc. 2004, 126, 3880-3891.

[9] a) M. J. Cook, A. P. Lewis, G. S. McAuliffe, V. Skarda, A. J. Thomson, J. L. Glasper, D. J. Robbins, J. Chem. Soc. Perkin Trans. II 1984, 1293-1301; b) A. Juris, V. Balzani, F. Barigelletti, S Campagna, P. I. Belser, A. Von Zelewsky, Coord. Chem. Rev. 1988, 84, 85-277.

[10] C. M. Elliott, E. J. Hershenhart, J. Am. Chem. Soc. 1982, 104 7519-7526.

[11] K. Willinger, K. Fischer, R. Kisselev, M. Thelakkat, J. Mater. Chem. 2009, 19, 5364-5376.

[12] L. Viau, K. Senechal, O. Maury, J.-P. Guégan, P. Dupau, L. Toupet, H. Le Bozec, Synthesis 2003, 2003, 0577-0583. M. C. Carey, S. L. Adelman, J. K. McCusker, Chem. sci. 2019, 10, 134-144.

O. Maury, J.-P. Guégan, T. Renouard, A. Hilton, P. Dupau, N. Sandon, L. Toupet, H. Le Bozec, New J. Chem. 2001, 25, 15531566.

a) J. Karges, P. Goldner, G. Gasser, Inorganics 2019, 7, 4; bY. Ellahioui, M. Patra, C. Mari, R. Kaabi, J. Karges, G. Gasser, S. Gómez-Ruiz, Dalton Trans. 2019, 48, 5940-5951.

[16] a) M. Patra, T. Joshi, V. Pierroz, K. Ingram, M. Kaiser, S. Ferrari, B. Spingler, J. Keiser, G. Gasser, Chem. Eur. J. 2013, 19, 1476814772; b) U. Basu, J. Karges, F. Chotard, C. Balan, P. Le Gendre, G. Gasser, E. Bodio, R. Malacea Kabbara, Polyhedron 2019, in press doi.org/10.1016/j.poly.2019.1002.1041; c) H. Huang, N. Humbert, V. Bizet, M. Patra, H. Chao, C. Mazet, G. Gasser, J. Organomet. Chem. 2017, 839, 15-18; d) A. K. Renfrew, J. Karges, R. Scopelliti, F. D. Bobbink, P. Nowak-Sliwinska, G. Gasser, P. Dyson, ChemBioChem 2019, accepted.

[17] S. J. Bruce, I. Tavazzi, V. r. Parisod, S. Rezzi, S. Kochhar, P. A. Guy, Anal. Chem. 2009, 81, 3285-3296.

J. W. Dobrucki, J. Photochem. Photobiol. B 2001, 65, 136-144. I. Bratsos, E. Alessio, Inorg. Synth. 2010, 35, 148-152. Rigaku Oxford Diffraction 2015. R. Clark, J. Reid, Acta Crystallogr. Sect. A: Found. Crystallogr 1995, 51, 887-897.

CrysAlisPro (version 1.171.39.13a), Rigaku Oxford Diffraction 2016

[23] O. V. Dolomanov, L. J. Bourhis, R. J. Gildea, J. A. K. Howard, H. Puschmann, J. Appl. Crystallogr. 2009, 42, 339-341. G. M. Sheldrick, Acta Crystallographica Section A: Foundations and Advances 2015, 71, 3-8. 
[25] G. M. Sheldrick, Acta Crystallographica Section C: Structural Chemistry 2015, 71, 3-8.

[26] C. F. Macrae, P. R. Edgington, P. McCabe, E. Pidcock, G. P. Shields, R. Taylor, M. Towler, J. v. d. Streek, J. Appl. Crystallogr 2006, 39, 453-457.

[27] K. Nakamaru, Bull. Chem. Soc. Jpn. 1982, 55, 1639-1640.

[28] I. E. Kochevar, R. W. Redmond, in Methods Enzymol., Vol. 319, Academic Press 2000, pp. 20-28. 


\section{FULL PAPER}

The preparation and characterisation of new $\mathrm{Ru}$ (II)-containing photodynamic therapy, that are based on a $\left[\mathrm{Ru}(\text { bipy })_{3}\right]^{2+}$ core (bipy: 2,2'-bipyridine) and that are extended with methyl groups or vinyl dimethylamino groups is described. Their in-depth photophysical properties as well as (photo-)cytotoxicity against cervical cancerous HeLa cells is also reported.

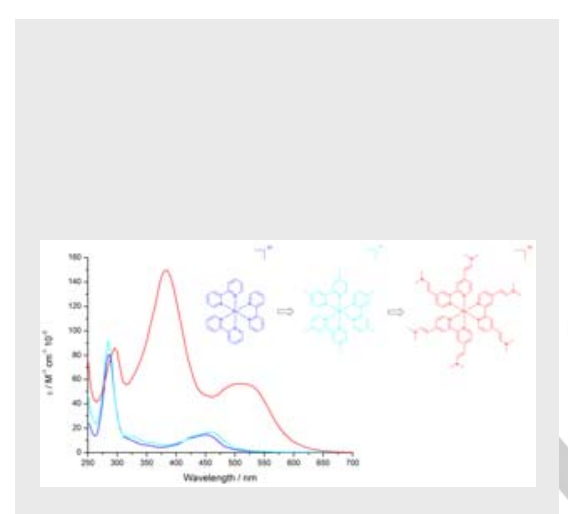

Key Topic: Metals in Medicine • Photodynamic Therapy

Johannes Karges, Olivier Blacque,

Philippe Goldner and Gilles Gasser *

Towards Long Wavelength Absorbing

Photodynamic

Therapy

Photosensitizers via the Extension of a $\left.[\mathrm{Ru} \text { (bipy) })_{3}\right]^{2+}$ Core 